\title{
The Outcome Of Using The Cognitive Stimulation Therapy On Demented Elderly In Malaysia
}

\author{
Stella Wong Jing Yong, Low Sew Kim, Pheh Kai Shuen*
}

Faculty of Arts and Social Science, UniversityTunku Abdul Rahman, JalanUniversiti Bandar Barat, 31900, Kampar, Perak, 31900, Malaysia

*Corresponding author: phehks@utar.edu.my

\begin{abstract}
The Malaysian government estimated that in 2013,5.5\% of the Malaysian population comprises of senior citizens aged 60 years old and above. Recent research had revealed that $14.3 \%$ of the older Malaysians are at risk of Major Neurocognitive Disorder (MND; also known as dementia). As the elderly population increases gradually in the country, the chances of them suffering from MND are also expected to increase. MND is often associated with a decline in memory or thinking skills which are severe enough to affect the ability to perform everyday activities among those who are diagnosed with these symptoms. Cognitive Stimulation Therapy (CST) is a brief treatment for those suffering from mild to moderate MND. However, the efficacy of this treatment has not been evident in Malaysia.The aim of the present study is to identify the effectiveness of CST in stabilizing the declination of cognitive functions, as well as improving the quality of life among elderly suffering from mild to moderate MND. Thirty elderly diagnosed with mild and moderate MND will be invited to participate in a single group pre-post trial, involving a 45 minute CST treatment to be administered for 14 weeks on a regular weekly basis. The participants will be selected from residents of care centers elderly at Klang Valley area. The outcomes and effectiveness of the CST will be determined by the Montreal Cognitive Assessment (MoCA), and Quality of Life-Alzheimer's Disease (QOL-AD). The former instrument will be used to examine the cognitive abilities of the elderly, while the latter will be used to determine issues related to the quality of life based on the participant and caregivers rating report. As the CST efficacies has been proven in several countries such as the United Kingdom, Hong Kong and Japan, the present study anticipates that it will also be effective in the Malaysia context and helps in treating MND.
\end{abstract}

Keywords: Dementia, elderly, quality of life, Malaysia, cognitive stimulation therapy

(C) 2017 Penerbit UTM Press. All rights reserved

\subsection{INTRODUCTION}

Malaysia has been undergoing a drastic growth of elderly population, a phenomenon which is congruent with many countries across the world. In year 2013, about 5.5\% of Malaysian population are citizens which is above the age of 60 (Department of Statistics, 2013). The population was expected to double in between year 2010 to 2040 and when the population is aging, the people who suffer from Neurocognitive Disorder (NCD; including dementia) might also increase. Hamid, Krishnaswamy, Abdullah, and Momtaz (2010), study showedthat the overall prevalence rate of dementia in Malaysia was around 14.3\%. This prevalence figure of dementia was higher than the majority countries of Asia Pacific and it may be due to certain factors such as education background, ethnicity and sociodemographic differences of Malaysia citizens.

As stated in the Diagnostic and Statistical Manual of Mental Disorder, Fifth Edition (American Psychological Association, 2013), the diagnostic criteria for mild NCD includes the decline of cognitive functioning as compared to the individual's prior performance in single or multiple cognitive domains. However, an individual should still be able to function in daily activities such as paying bills and managing their own medication. Also, cognitive tests are available in detecting NCD. The Montreal Cognitive Assessment (MoCA) is also helpful in detecting mild cognitive impairment such as dementia (Nasreddine et al., 2005). There are also evidence that positron emission tomography (PET) scan could also detect dementia as elderly with dementia will have lower metabolic rates in the parietal and temporal region of the brain (Alexander et al., 2002). The Magnetic resonance imaging (MRI) with the combination of both assessment and neuroimaging, helps in the accurate and effective detection of dementia.

To date, many research and drug trials have been used to cure and slow down the dementia progress. However, the success was limited. The cost of developing and testing new drugs and treatments to slow down the progression of dementia has been increasing (Schaller et al., 2015). In the study by Wimo et al. (2013), the dementia care will need big amount of money in sustaining the long-term care towards individuals with dementia. In a long run, this will bring an impact on the country's economic status. The cost spent on dementia society annually was reported to be as high as 604 billion US dollars. Also, research found that individual who is having dementia is also closely associated with the risk of being admitted to the hospital as individuals with dementia are declining in their cognition and the inability of performing ordinary daily activities (Russ et al., 2015). According to Prince et al. (2012), risk of dementia will be depending on factors such as increasing of age, gender and education level. The brain reserve which includes the effects of education, intelligence level, occupation, and mental function is also closely related to the incidence of dementia. Also, citizens in developing country will have earlier onset of dementia as they have limited education and occupation attainment. The characteristic of forgetful in elderly person were perceived as something normal in the societyof Asian countries such as Malaysia (Nikmat, Hawthorne\& Al-Mashoor, 2011). Also, Penders et al. (2014) has reported that one fourth of the family and relative caregivers were unaware that their relatives were suffering from dementia. As a result, it is a challenge to implement quality health care for the elderly with dementia. The major consequences of dementia is that individual will lost their autonomy, they will not taking the opportunity to act and participate in social activities. Therefore, in a long run, people who suffer from dementia will find their quality of life to be decreasing (Graff et al., 
2006). In Malaysia, putting dementia patients in nursing home or residential care center is being interpreted as abandonment and it is forbidden from the religious and cultural point of view (Mackenzie, 2006). However, according to Etters, Goodall, and Harrison (2008), taking care of dementia patient contributes psychological burden and mental distress towards the caregiver.

There are dozens of effort to deal with dementia. First of all, there was intervention that aims to provide training to care givers in dealing with elderly with dementia. According to Jeon et al. (2013), the multi-component education toolkit was developed to aid the care givers in managing elderly with dementia's behavioral and psychological symptoms of dementia. Similarly, in a research on supporting the Asian population of elderly with dementia with non-pharmacological psychosocial intervention, give them support in reducing and managing the symptoms of dementia and will leads to a better quality of life (Westphal, Hall, \& Chiu, 2011).The Cognitive Stimulation Therapy (CST) is one of the psychosocial interventions thathave been used in treating elderly patients who are suffering from dementia to increase the cognition and quality of life. Also, according to Spector, Orrell, and Woods (2010), CST also plays an important role in improving the language functioning of dementia patients. This is particularly effective because they learn how to generate semantic links by categorization. In addition, CST also indirectly improved their quality of life as they are able to talk and communicate more with people around them. As compared to other types of psychological therapy, CST is cost-effective (Knapp et al., 2006). The CST was also found to be effective in reducing the risk of getting dementia. Moreover, CST also shows positive effect on dementia patients whether they are having medication or not (Woods et al., 2012; Chapman et al., 2004; Onder et al., 2005; Bottino et al., 2005).A manual of CST has been published by Spector et al. (2006) which contain instructions and materials needed in conducting the session. In the current study, researcher will be conducting Malaysia adapted CST. There will be 14 session and each session will lasts for 45 minutes. Participants will be assigned to a group of maximum 6 people as suggested in the CST manual. At the beginning, the orientation board will be introduced to each group. Then, information such as the group name and theme song will be written on the board for member's reference. The session will have various combinations of sensory stimulating activities involving touch, vision, hearing, taste and smell. Also, the CST sessions involves physical games, sound or music games, recalling on childhood memories, activity related to food, current affairs, faces, word association, creativity, categorizing objects, orientation, using money, number games, word games and team quiz.

There is positive evidence found by using CST on person who is suffering from dementia (Aguirre et al., 2013). Whereby the results shows that after participating CST, people with dementia shows better in cognitive performance and quality of life. A better outcome on behavior was also found in prior research. Also, Yamanaka, Kawano, Noguchi, Nakaaki, Watanabe, Amano, and Spector, (2013) has replicated a United Kingdom study and found that CST is also effective in Japan. However, CST received little attention in Malaysia as compare to other countries. Although CST has been proven to be beneficial in other country, only few practitioners were trained on it in Malaysia.Therefore, the current research is to determine the effectiveness of CST in Malaysia context and also to benefit dementia patients so that they could maintain their cognitive functioning and leads to a better life. It is also vital to let practitioners and caregivers know that other than medication, there are also psychosocial therapies available to aid those who are suffering from dementia.The Cognitive Stimulation Therapy (CST) is proposed to benefit people with dementia. According to Spector et al. (2003), CST is a beneficial way to increase an individual's cognitive as well as the quality of life. The purpose of this research is to adapt CST into Malaysia context and examine its feasibility. It is expected that the CST will help in maintaining the quality of life and cognitive functioning in elderly population. It is very important to maintain the health and quality of life of the aging population so that they could live independently. In that way, they could feel more confident and comfortable in their life.

\subsection{THEORETICAL FOUNDATION OF THE STUDY}

According to Woods, Thorgrimsen, Spector, Royan, and Orrell (2006), CST was developed based on the Cochrane systematic review of the Reality orientation (RO) and reminiscence therapy.

\section{Reality Orientation (RO)}

RO was an approach developed initially for the patients with psychiatric problems. According to the philosophy of RO, the mental state of an individual could be improved by mental stimulation and interacting with others (Patton, 2006). Recently, researcher has been modifying RO to suit in to the context of dementia. According to Folsom (1968) RO consist of 3 components which is the maintenance of a specific attitude towards the patient, stimulating patient by presenting basic orienting information and forming of group which contain a small group of 3 to 6 individuals. Also, RO was suggested to improve individual with dementia's sense of control and selfesteem as it reduces the feeling of helplessness. Individual who suffers from dementia will gain a sense of competence because the activity which is being carried out is appropriate to the ability of the individual.

\section{Reminiscence Therapy (RT)}

The development of reminiscence therapy (RT) was based on the claim that individual at the later stage of dementia will have clear memory of early life (Norris, 1986). Therefore, those memories were used to communicate with the elderly with dementia. During the RT, past memories or events were recalled with the help of tools such as photographs, household items or familiar objects from the past. The process of discussing the past events will help in improving the quality of life, behavior as well as communication (Haight, Gibson, \& Michel, 2006); maintaining self-esteem and self-identity (Schweitzer, 2007).

\subsection{CONCEPTUAL FRAMEWORK}

After reviewing several past literatures on CST and dementia, a model (Figure 1) had been illustrated that after undergoing the CST, it will leads to a better quality of life and cognitive functioning. The domains that fall under the cognitive functioning include the attention and concentration, executive functioning, memory, language, visuoconstructional skills, conceptual thinking, calculations and orientation. Rather than looking at the cognitive functioning as a whole, the current study will also identify the specific domain which will be improved with the CST. 


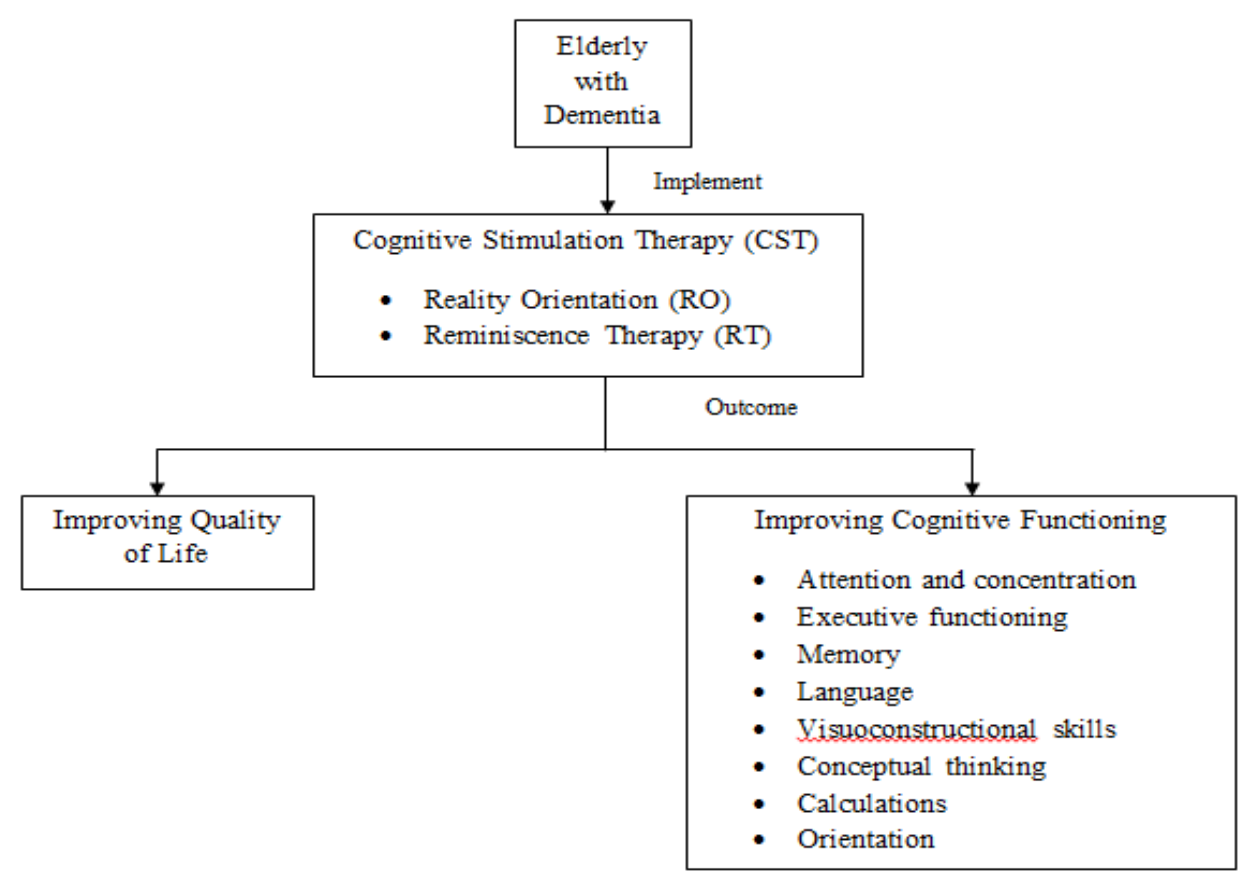

Figure 1 The framework of CST in improving the elderly with dementia's quality of life and cognitive functioning.

\subsection{METHODOLOGY}

\section{Research Design}

The current research will be a single group pre-post trial in determining the efficacy of CST. Two instruments were selected to examine the cognitive functioning and quality of life of the elderly who is living in the elderly care center. The result generated will then give an insight to the researcher to conclude on the outcome of using the CST onelderly with dementia. The targeted participants of this study will be elderly Malaysian who are currently staying in elderly care center.Participants will be recruited from fourcentersaround Klang Valley. A list of potential participant is generated by using the purposive method. Initially, the participant has to meet certain criteria in order to be included in the study, which is (1) 65 years old and above, (2) scored 10 to 25 in the MoCAand (3) currently staying in anelderly care center. From the list, thirty participants were recruited and then distributed using randomization method into treatment and control group. All of the individual in the list will have an equal chance of being included in the current study to eliminate bias in the current study. The study was approved by Scientific Research Ethics Committee of University Tunku Abdul Rahman(U/PSPN/27/2015).

\section{Instruments}

\section{Montreal Cognitive Assessment (MoCA)}

The MoCA includes variety of domains which is screening on the cognitive functioning of an individual. The domains of the assessment include attention and concentration, executive functions, memory, language, visuoconstructional skills, conceptual thinking, calculations, and orientation. The total score of MoCA is 30, individual who scored 26 or above is considered as normal. Whereas for individuals who scored 10 to 25 points will be assuming to have mild cognitive impairment (Nasreddine et al., 2005). The assessment requires to spend around 10 minutes to complete. According toRazali et al., MoCA has been adapted in Malaysia with internal consistency of 0.80 and correlation with the MMSE of 0.77 .

\section{Quality of Life-Alzheimer's Disease (QOL-AD)}

To assess the quality of life of the elderly with dementia, QOL-AD was used in the current study. The QOL-AD will be distributed to the participant and their care givers. The total items of the instrument was 13 which includes the domain of physical health, energy, mood, living situations, memory, family, marriage, friends, chores, fun, financial, self and life as a whole of the participants. All of the item will be rated by the participants according to a 4-point likert scale which ranged from 1 (poor) to 4 (excellent). At the end, analysis of the total rating will be done based on participant and care giver's rating. However, the participant's rating will be weighted twice as heavy as the care giver's rating as their opinion is more important. Also, The QOL-AD has a validity of 0.69 as a result of correlation with the Demential Quality of Life scale and test-retest reliability of 0.92 (Logsdon et al., 1999). 


\subsection{DISCUSSION}

The study aimed to determine the outcomes and effectiveness of the CST towards elderly with dementia. For the expected result, the post test of the MoCA and QOL-AD score is estimated to be higher as compared to the pre test scores. This is because CST is expected to help in increasing the cognitive ability as well as the quality of life of the elderly with dementia(Spector, Orrell, and Woods, 2010). Rather than looking at the cognitive functioning as a whole, this study also looks into the different dimension such as the attention and concentration, executive functions, memory, language, visuoconstructional skills, conceptual thinking, calculations and orientation of the participant for a more diverse perspective. This study is expected contribute in improvingwell-being of elderly with dementiato make them more independent and comfortable in the own life. In addition, the burden of the care givers will also lessen as the participants are able to be more independent (Etters, Goodall, \& Harrison, 2008). By undergoing CST, we wish thatelderly with dementiawill gain a sense of being understood by others, gaining confidence in communicating with others, increase attention and focus on task based activities. Therefore, it may also improve the sense of competence (Mason, Clare, \&Pistrang, 2005).Therefore, if CST is proven to be effective in Malaysia context, caregivers and workers in the elderly care center should be given proper training on the CST.It is important to implement the CST widely in the elderly care centers to benefit demented as well as normal elderly in reducing risk of getting dementia (Woods et al., 2012).

\section{References}

Alexander, G. E., Chen, K., Pietrini, P., Rapoport, S. I., \& Reiman, E. M. (2002). Longitudinal PET Evaluation Of Cerebral Metabolic Decline In Dementia: A Potential Outcome Measure In Alzheimer's Disease Treatment Studies. American Journal of Psychiatry, 159(5), 738-745.

American Psychological Association (2013). Statistical Manual of Mental Disorders: DSM-V. American Psychiatric Publishing. Washington, DC.

Bottino, C. M., Carvalho, I. A., Alvarez, A. M. M., Avila, R., Zukauskas, P. R., Bustamante, S. E., \& Camargo, C. H. (2005). Cognitive Rehabilitation Combined With Drug Treatment In Alzheimer's Disease Patients: A Pilot Study. Clinical Rehabilitation, 19(8), 861-869.

Chapman, S. B., Weiner, M. F., Rackley, A., Hynan, L. S., \&Zientz, J. (2004). Effects of Cognitive-Communication Stimulation For Alzheimer's Disease Patients Treated Withdonepezil. Journal of Speech, Language, and Hearing Research, 47(5), 1149-1163. Retrieved from http://jslhr.pubs.asha.org/article.aspx?articleid=1781496

$\begin{array}{llllll}\text { Department } & \text { of } & \text { Statistic } & \text { (2013). } & \text { Population } & \text { Projection, }\end{array}$ http://www.statistics.gov.my/portal/download_Population/files/population_projections/Population_Projection_2010-2040.pdf

Etters, L., Goodall, D., \& Harrison, B. E. (2008). Caregiver Burden Among Dementia Patient Caregivers: A Review Of The Literature. Journal of the American Academy of Nurse Practitioners, 20(8), 423-428.

Folsom, J. C. (1968). Reality Orientation For Elderly Mental Patient. Journal of Geriatric Psychiatry, 1(2), 291-307.

Folstein, M. F., Folstein, S. E., \& McHugh, P. R. (1975). "Mini-Mental State": A Practical Method For Grading The Cognitive State Of Patients For The Clinician. Journal Of Psychiatric Research, 12(3), 189-198.

Graff, M. J., Vernooij-Dassen, M. J., Thijssen, M., Dekker, J., Hoefnagels, W. H., \&Rikkert, M. G. O. (2006). Community Based Occupational Therapy For Patients With Dementia And Their Care Givers: Randomised Controlled Trial. Bmj, 333(7580), 1196. Retrieved from http://www.ncbi.nlm.nih.gov/pmc/articles/PMC1693594/

Haight, B. K., Gibson, F., \& Michel, Y. (2006).The Northern Ireland Life Review/Life Storybook Project For People With Dementia. Alzheimer's \& Dementia, 2(1), 56-58.

Hamid, T. A., Krishnaswamy, S., Abdullah, S. S., \& Momtaz, Y. A. (2010). Sociodemographicrisk factors and correlates of dementia in older Malaysians.Dementia and Geriatric Cognitive Disorders, 30(6), 533-539.Retrieved fromhttp://www. karger.com/Article/FullText/321672

Jeon, Y. H., Govett, J., Low, L. F., Chenoweth, L., Mcneill, G., Hoolahan, A.,\& O’Connor, D. (2013). Care Planning Practices For Behavioural And Psychological Symptoms Of Dementia In Residential Aged Care: A Pilot Of An Education Toolkit Informed by the Aged Care Funding Instrument. Contemporary Nurse, 44(2), 156-169.

Knapp, M., Thorgrimsen, L., Patel, A., Spector, A., Hallam, A., Woods, B., \&Orrell, M. (2006).Cognitive Stimulation Therapy For People With Dementia: Cost Effectiveness Analysis. The British Journal of Psychiatry, 188(6), 574-580.

Logsdon, R. G., Gibbons, L. E., McCurry, S. M., \& Teri, L. (1999). Quality of Life In Alzheimer's Disease: Patient And Caregiver Reports. Journal of Mental Health and Aging, 5, 21-32.

Mackenzie, J. (2006). Stigma and Dementia East European And South Asian Family Carers Negotiating Stigma in the UK. Dementia, 5(2), $233-247$.

Mason, E., Clare, L., \&Pistrang, N. (2005).Processes and Experiences Of Mutual Support In Professionally-Led Support Groups For People With Early-Stage Dementia. Dementia, 4(1), 87-112.

Nasreddine, Z. S., Phillips, N. A., Bédirian, V., Charbonneau, S., Whitehead, V., Collin, I., \&Chertkow, H. (2005). The Montreal Cognitive Assessment, MoCA: A Brief Screening Tool For Mild Cognitive Impairment. Journal of the American Geriatrics Society, 53(4), 695-699. Retrieved from http://onlinelibrary.wiley.com/doi/10.1111/j.15325415.2005.53221.x/abstract?userIsAuthenticated=false\&deniedAccessCustomisedMessage=

Nikmat, A. W., Hawthorne, G., \& Al-Mashoor, S. H. A. (2011). Dementia in Malaysia: Issues And Challenges. Advisory Board, Associate Editors, Reviewers and Editorial Board Members, 85, 95.

Norris, A. (1986). Reminiscence: With Elderly People. Winslow.

Onder, G., Zanetti, O., Giacobini, E., Frisoni, G. B., Bartorelli, L., Carbone, G., ...\&Bernabei, R.(2005). Reality Orientation Therapy Combined With Cholinesterase Inhibitors In Alzheimer's Disease: randomised controlled trial. The British Journal of Psychiatry, 187(5), 450-455. Retrieved from http://bjp.rcpsych.org/content/187/5/450.short

Patton, D. (2006). Reality Orientation: Its Use And Effectiveness Within Older Person Mental Health Care. Journal of Clinical Nursing, 15(11), 1440-1449.

Penders, Y. W., Albers, G., Deliens, L., Vander Stichele, R., Van den Block, L., De Groote, Z., . \& Payne, S. (2014). Awareness of Dementia By Family Carers Of Nursing Home Residents Dying With Dementia: A Post-Death Study. Palliative Medicine, 0269216314542261.

Prince, M., Acosta, D., Ferri, C. P., Guerra, M., Huang, Y., Rodriguez, J. J. L.,\& Liu, Z. (2012). Dementia Incidence And Mortality In Middle-Income Countries, And Associations With Indicators Of Cognitive Reserve: a 10/66 Dementia Research Group Population-Based Cohort Study. The Lancet, 380(9836), $50-58$.

Razali, R., Jean-Li, L., Jaffar, A., Ahmad, M., Shah, S. A., Ibrahim, N., \& Ahmad, S. (2014). Is theBahasa Malaysia version of the Montreal Cognitive Assessment (MoCA-BM) a Better Instrument Than The Malay Version of the Mini Mental State Examination (M-MMSE) in Screening For Mild Cognitive Impairment (MCI) In The Elderly?. Comprehensive Psychiatry, 55, S70-S75.

Russ, T. C., Parra, M. A., Lim, A. E., Law, E., Connelly, P. J., \&Starr, J. M. (2015). Prediction of General Hospital Admission In People With Dementia: Cohort Study. The British Journal of Psychiatry, 206(2), 153-159.

Schaller, S., Mauskopf, J., Kriza, C., Wahister, P., \& Kolominisky-Rabas, P. (2015). Pay Me Now Or Pay Me Later: Dementia And The Cost Of Health Care. Int J Geriatr Psychiatry, 30, 111-29.

Schweitzer, P. (2007). Reminiscence Theatre: Making Theatre From Memories. Jessica Kingsley Publishers.

Spector, A., Orrell, M., \& Woods, B. (2010). Cognitive Stimulation Therapy (CST): Effects on Different Areas Of Cognitive Function For People With Dementia.International Journal Of Geriatric Psychiatry, 25(12), 1253-1258.

Spector, A., Thorgrimsen, L., Woods, B. O. B., Royan, L., Davies, S., Butterworth, M., \&Orrell, M. (2003). Efficacy of an Evidence-Based Cognitive Stimulation Therapy Programme For People With Dementia Randomised Controlled Trial. The British Journal of Psychiatry, 183(3), 248-254.

Spector, A., Thorgrimsen, L., Woods, B., \&Orrell, M.(2006).Making a Difference: An Evidence-Based Therapy Programme To Offer Cognitive Stimulation Therapy (CST) To People With Dementia. UK: Hawker. 
Westphal, A., Hall, W., \& Chiu, E. (2011).Opinion Enhancing Quality Of Life In Dementia. Asia-Pacific Psychiatry, 3(3), $103-106$.

Wimo, A., Jönsson, L., Bond, J., Prince, M., Winblad, B., \& International, A. D. (2013).The Worldwide Economic Impact Of Dementia 2010. Alzheimer's \& Dementia, 9(1), 1-11.

Woods, B., Aguirre, E., Spector, A. E., \& Orrell, M. (2012). Cognitive stimulation to improve cognitive functioning in people with dementia. The Cochrane Library.

Woods, B., Thorgrimsen, L., Spector, A., Royan, L., \&Orrell, M. (2006). Improved Quality Of Life And Cognitive Stimulation Therapy In Dementia.Aging and Mental Health, 10(3), 219-226. 